\title{
Convenient and Efficient Suzuki Miyaura Coupling Reactions of Meso-Halogenated BODIPYs
}

\author{
Gökçe Hilal Taşan ${ }^{1}$, Raşit Fikret Yılmaz ${ }^{2}$, Yavuz Derin ${ }^{1}$, Büşra Albayrak Mısır ${ }^{1}$, $\underline{\text { Ahmet Tutar }^{1}}$ \\ 1. Faculty of Arts and Sciences,Department of Chemistry, Sakarya University, TURKEY, Sakarya 54187, \\ E-mail: gokce.tasan@ogr.sakarya.edu.tr; yavuzderin@sakarya.edu.tr; bursa.albayrak4@ogr.sakarya.edu.tr; \\ atutar@sakarya.edu.tr
}

2. Department of Fundamental Sciences, Turkish Naval Academy, National Defence University, TURKEY, İstanbul, 34940, E-mail: rfyilmaz@,dho.edu.tr

\begin{abstract}
In this study, we synthesized new conjugated BODIPY compounds with potential fluorescence by treated the BODIPY compound containing bromine in the meso position with different boronic acids. BODIPY cores derived from meso position are used in interesting applications such as pH probe and redox sensors.
\end{abstract}

Keywords - BODIPY, halogenated BODIPY, Suzuki-Miyaura coupling reactions, boronic acids, photophysical and electrochemical properties.

\section{Introduction}

Boradiaza-s-indacene (boron dipyrrin or boron dipyrromethene, BODIPY) dyes have gained outstanding place for use in fluorescent materials, labels, and probes. Derivatization at the 8-position, or meso-position, is a preferred method for the construction of complex BODIPY fluorophores. The nature of the new substituent has strong influence on the spectral properties of the dyes [1]. Spectroscopic features can be easily accommodated by different synthetic strategies on BODIPY nucleus [2]. Halogenated BODIPYs are important precursors to synthesize a variety of substituted BODIPYs and potential sensitizers for photodynamic therapy (PDT). Halogenated systems can be derivatized by transition metal catalyzed cross-coupling reactions [3].

The palladium-catalyzed Suzuki cross-coupling reaction is one of the most efficient methods for the construction of $\mathrm{C}_{\text {aryl }}-\mathrm{C}_{\text {aryl }}$ bonds and has found widespread use in organic synthesis. Carboncarbon bond formation reactions are some of the most important processes in chemistry, that provide key steps in the building of more complex molecules from simple precursors [4].

\section{Conclusion}

In this study, 4,4-difluoro-8-(4-bromophenyl)-4-bora-3a,4a-diaza-s-indacene (BODIPY) was synthesized from reaction of pyrrole with 4-bromobenzaldehyde and complexation with $\mathrm{BF}_{3}$. $\mathrm{OEt}_{2}$. The synthesized BODIPY nucleus was treated with different boronic acids and new BODIPY compounds derived from the 8-position were obtained.

\section{Acknowledgments}

This study is supported by the the Scientific Research Projects Unit of Sakarya University (BAP-2020-7-24-54).

\section{References}

[1] Leen, V., Yuan, P., Wang, L., Boens, N., Dehaen, W. (2012). Synthesis of Meso-Halogenated BODIPYs and Access to Meso-Substituted Analogues. Organic Letters, 14 (24) 6150-6153. https://doi.org/10.1021/ol3028225

[2] Derin, Y., Yılmaz, R. F., Baydilek, I. H., Atalay, V. E., Ozdemir, A., Tutar,A. (2018). Synthesis Electrochemical/Photophysical Properties and Computational Investigation of 3,5- dialkyl BODIPY Fluorophores. Inorganica Chimica Acta, 482, 130-135. https://doi.org/10.1016/j.ica.2018.06.006

[3] Lakshmi, V., Ravikanth, M. (2012). Brominated Boron Dipyrrins. Synthesis, Structure, Spectral an Electrochemical Properties. Dalton Transactions, 41, 5903-5911. https://doi.org/10.1039/C2DT00019A

[4] Suzuki, A. (2002). Cross-coupling Reactions via Organoboranes. Journal of Organometallic Chemistry 653 (1-2) 83-90. https://doi.org/10.1016/S0022-328X(02)01269-X 